Article

\title{
Probing Chemical Changes in Holocellulose and Lignin of Timbers in Ancient Buildings
}

\author{
Chencheng Zhao ${ }^{1,+}{ }^{+}$Xiaochun Zhang ${ }^{1,+}$, Lina Liu ${ }^{1}$, Youming $\mathrm{Yu}{ }^{1, *}$, Wei Zheng ${ }^{2, *}$ and \\ Pingan Song ${ }^{1, *}$ \\ 1 School of Engineering, Zhejiang A\& F University, Hangzhou 311300, China; \\ chenchengzhao0918@163.com (C.Z.); 20110039@zafu.edu.cn (X.Z.); liulina198310@126.com (L.L.) \\ 2 Jiyang College, Zhejiang A\& F University, Zhuji 311800, China \\ * Correspondence: yuyouming@zafu.edu.cn (Y.Y.); 19990019@zafu.edu.cn (W.Z.); \\ pingansong@gmail.com (P.S.); Tel.: +86-0571-6374-3976 (Y.Y.); +86-0575-8776-0083 (W.Z.); \\ +86-0571-6374-3976 (P.S.) \\ + These two authors equally contributed to the work and serve as co-first authors.
}

Received: 20 March 2019; Accepted: 30 April 2019; Published: 6 May 2019

check for updates

\begin{abstract}
Wooden structures in China's ancient buildings hold highly historical and cultural values. There is an urgent need to repair and replace the damaged wooden structures after hundreds and thousands of years of exposure to weather. Unfortunately, to date there is still a lack of insightful understanding on how the chemical structure, composition, and micro-morphology evolve over the long-term natural aging before artificial ancient timbers can be developed. This work aims to systematically examine the outer surface, middle layer, and inner surface of the same piece of Chinese fir (Cunninghamia lanceolate) collected from an ancient Chinese building. Based on qualitative and quantitative analysis, both cellulose and hemicellulose in aged woods are found to experience significant degrees of degradation. The crystalline regions of cellulose are also determined to undergo moderate degradation as compared to the control fresh wood. In comparison, the lignin basically remains unchanged and its content in the inner layer slightly increases, as evidenced by more free phenol groups determined. Relative to the outer and inner layer, the middle layer of the ancient wood shows the lowest degree of degradation close to that of the fresh wood. This work offers guidelines for fabricating artificial ancient woods to repair the destroyed ones in China's ancient architectures.
\end{abstract}

Keywords: aged timbers; ancient building; chemical analysis; structure evolution; morphology

\section{Introduction}

Wood culture is one of the most cultural heritages from ancient China, which has been handed down from generation to generation. In ancient China, most residences and temples are made of wood. As shown in Figure 1, wooden objects from old civilizations are considered precious and require careful storage and research, because they are susceptible to fungi, bacteria, and insects. As a result, after many years a vast majority of wooden structures in ancient buildings are significantly damaged, leaving only a small portion remains intact. The damage to the timbers in ancient buildings are irreversible and thus reparation and/or replacement are generally required to protect these historic ancient buildings. With the increasing awareness of protection of historical relics, the reparation of ancient architecture has become necessary. In order to develop efficient antique treatments to fresh woods, it is essential to gain an insightful understanding on the evolution of chemical/composition changes of the wooden structures during natural ageing [1]. 


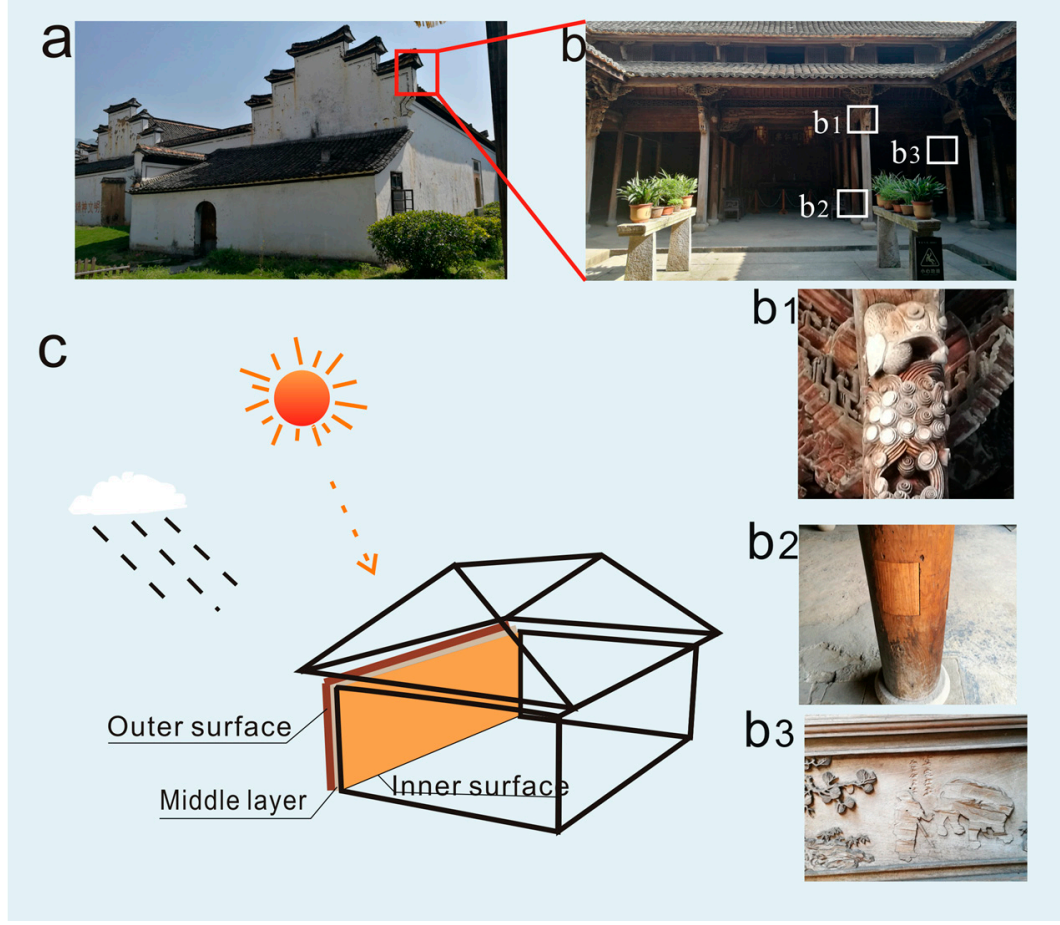

Figure 1. Damage and reparation of typical ancient wood buildings (a: ancient wooden building exterior view; $\mathbf{b}$ : ancient wooden building interior view; b1\&b2: damaged wood carving; and b3: repaired with fresh wood; c: The specific positions for taking samples).

Recently, the research on natural aging of wood has attracted extensive attentions. Carmen et al. [2-4] studied wood with different natural aging time and the results found that the proportion of carbohydrate gradually decreases, and the content of lignin increases successively with increasing time. This is due to the degradation of hemicellulose, which was mainly manifested in the decomposition of polyxylan. Michel et al. employed the solid-state nuclear magnetic resonance (SSNMR) to analyze the medieval canoe immersed by water and found that polysaccharides significantly degraded and hemicellulose almost completely degraded, however, the $\beta-\mathrm{O}-4$ key of lignin remained [5]. Maria et al. detected the existence of free phenols from archaeological waterlogged wood [1], whereas Anna et al. investigated the physico-chemical characteristics of oak and Pinus densiflora being submerged by water [6]. Both researchers provided the theoretical basis for the studies on the degradation mechanism of lignin. Tamburini et al. pyrolyzed archaeological waterlogged wood followed by analyzing using mass spectroscopy (MS). The results show that polysaccharides degraded significantly and the relative content of lignin was increased [7]. Colombini et al. found that most of the lignin was acetylated, the molecular weight of lignin increased, and the phenmethyl groups near to the $\beta-\mathrm{O}-4$ bond were oxidized [8].

Generally, cellulose, hemicellulose, and lignin in wood undergo different extent of change during natural aging. The changes of three components have been widely examined in the aging process of wood. Lucejko JJ et al. showed that the degradation of fiber bundles and other sugars were catalyzed in water but the overall structural changes of lignin did not occur [9]. In all waterlogged ancient wood samples, $\beta-\mathrm{O}-4$ chains were not destroyed. Saiz-Jimenez $\mathrm{C}$ et al. [10] reported that the degradation of lignin was more difficult than other components and only a small percentage of lignin is decomposed by fungi and bacteria. In water environments, microbial is the main factor of wooden degradation, which is why some wood antiquities, such as shipwrecks, are easier to preserve. Karami L et al. studied the degradation of naturally aging oak bridge by using pyrolysis gas chromatography-mass spectrometry (Py-GC/MS) and the ratio of lignin and carbohydrate was found to increase, whereas S-type and G-type lignin units decrease, reflecting the different degree of degradation of different 
components in the aging process [11]. The study on the degradation of lemon murals relics showed that the degradation of cellulose and hemicellulose caused the increased relative content of lignin [3]. Previous research has clearly demonstrated that both cellulose and hemicellulose experienced a great extent of degradation under light oxidation and microbial erosion, but the lignin remained intact in the process of natural aging. Despite great advances, there remains a lack of insightful understanding on how the chemical structure, composition and micromorphology of timbers in ancient buildings evolve during ageing.

This work aims to qualitatively and quantitatively probe the evolution of the chemical structure, relative content and micromorphology of timber in China's typical ancient buildings. Various analyses including Fourier transform infrared spectroscopy (FT-IR), Py-GC/MS, X-ray diffraction (XRD), X-ray photoelectron spectra (XPS), wood staining, scanning electron microscopy (SEM), and thermogravimetry (TG) are employed to determine the difference between fresh wood and ancient wood. This work provides valuable guidelines for creating artificial ancient woods to repair and replace the destroyed ones in China's ancient architecture.

\section{Materials and Methods}

\subsection{Materials}

Ancient wood samples were Chinese fir (Cunninghamia lanceolata) taken from an about 170 years old wooden building in Lishui City, Zhejiang Province, China. The wood samples were tagged as LS-M (samples from the half of the thickness of the wood), LS-I (the innermost layer of wood with a thickness of about $1 \mathrm{~mm}$ ), and LS-O (the outermost layer of wood with a thickness of about $1 \mathrm{~mm}$ ), respectively (Figure 1). The control sample (CS) was fresh wood with the same tree species of ancient wood samples. The specific positions for taking samples have been indicated in Figure 1c. The original materials were crushed and pulverized to a size of $<0.2 \mathrm{~mm}$, and oven-dried at $105^{\circ} \mathrm{C}$ before they were analyzed.

\subsection{Determination of Lignin, Cellulose, and Hemicellulose}

The content of holocellulose of the samples was determined by dissolving the lignin in acidified sodium chlorite solution [12]. The content of cellulose was determined according to the National Standard of GB/T 2677.10-1995 and GB/T 2677.8-1994 after dissolving the hemicellulose from the holocellulose and the difference between holocellulose and cellulose was reported as the hemicellulose content. The content of lignin were determined according to National Standard of GB/T 744-1989. Briefly, samples were first submitted to Soxhlet extraction with ethanol/toluene (1:2, v:v) [13] and then treated with $72 \mathrm{wt} . \%$. sulfuric acid to dissolve cellulose, hemicellulose and acid soluble lignin [14].

\subsection{Characterizations}

Fourier transform infrared spectrometer (NICOLET IMPACT410, NICOLET, Madison, WI, USA) was used to identify the functional groups of the components. The samples are produced by the potassium bromide tableting method with a scanning wavenumber range of $400-4000 \mathrm{~cm}^{-1}$, and the number of scanning times is 32 .

Py-GC/MS has been applied to evaluate the thermal decomposition behavior and to determine the pyrolysis products of polymers due to its rapidity, high sensitivity, and effective separation of complex mixed compounds [15-18]. Pyroprobe analytical pyrolyzer (CDS 5200, Chemical Data Systems, CDS Analytical, Oxford, PA, USA) in combination with GC/MS (Agilent Technologies 7890B / 5977B, Agilent Technologies, Palo alto, CA, USA) to investigate the distribution of lignin fast pyrolysis products. Approximately $0.5 \mathrm{mg}$ of sample was fed into the quartz pyrolysis tube. The pyrolysis temperature was set to rise from room temperature to $800{ }^{\circ} \mathrm{C}$, the fixed heating rate was $20^{\circ} \mathrm{C} / \mathrm{ms}$, the fixed residence time was $20 \mathrm{~s}$, and the transmission line and injector temperature were maintained at $300{ }^{\circ} \mathrm{C}$ and $300^{\circ} \mathrm{C}$, respectively. Chromatography was carried out by using an HP-5MS capillary column (inner 
diameter: $30 \mathrm{~m} \times 0.25 \mathrm{~mm} \times$ film thickness: $0.25 \mu \mathrm{m})$. The carrier gas was helium $(99.999 \%)$ with a constant flow rate of $3 \mathrm{~mL} / \mathrm{min}$, and the split ratio was 1:100. The furnace temperature was set from $40{ }^{\circ} \mathrm{C}$ (for $3 \mathrm{~min}$ ) to $280^{\circ} \mathrm{C}$ (for $3 \mathrm{~min}$ ) with a heating rate was $10^{\circ} \mathrm{C} / \mathrm{min}$. The mass spectra were obtained when the mass to charge ratio $(\mathrm{m} / \mathrm{z})$ was $50-400$ in electron impact ion source (EI) mode of 70 eV. Based on the National Institute of Science and Technology (NIST) library and related literatures, the organic evolutionary components corresponding to each chromatographic peak can be identified in the Mass Hunter workstation software. It has been proved that the absolute peak area can be used for the quantitative determination of aromatic compounds.

The XRD tests were carried out on a DZF-6210 (Shimadzu Corporation, Kyoto, Japan) X-ray diffractometer. The sample (60-100 mesh) was pressed into thin slices at room temperature. The intensity was measured as a function of the scattering angle $2 \theta$ by $\theta-2 \theta$ scan. The angle range was $5-35^{\circ}$ and the scanning speed is $2 \% \mathrm{~min}$. A degree of crystallinity CRx was determined by the Segal method [19], using the height of the (200) peak $\left(I_{200}, 2 \theta=22.7^{\circ}\right)$, and the minimum between the (200) and (110) peaks $\left(I_{\mathrm{AM}}, 2 \theta=18^{\circ}\right)$ by the following equation:

$$
\mathrm{CR}_{\mathrm{X}}=\frac{I_{200}-I_{\mathrm{AM}}}{I_{200}} * 100 \%
$$

$I_{200}$ represents both crystalline and amorphous material and $I_{\mathrm{AM}}$ represents only amorphous material.

Thermogravimetric analysis (TGA) tests were performed on a NETZSCH STA409C (NETZSCH, Selb, German) thermogravimetric analyzer. Typically, about $8.0 \mathrm{mg}$ of sample was heated from $30^{\circ} \mathrm{C}$ to $800{ }^{\circ} \mathrm{C}$ at a heating rate of $10^{\circ} \mathrm{C} / \mathrm{min}$ under nitrogen atmosphere.

Elemental analysis was performed on a Vario EL cube (elementar company, Frankfurt, German) automatic analyzer. Based on its Duma thermal decomposition means and dynamic gas separation technology (adsorption analysis principle), as well as the brilliant detecting methods. In order to achieve high accuracy, we measured a sample with a wide range of size distributions and concentrations. During the test, the temperature of the reducing pipe was $850^{\circ} \mathrm{C}$, the burning pipe was $1150{ }^{\circ} \mathrm{C}$ and the pressures of nitrogen and oxygen were $0.15 \mathrm{MPa}$ and $0.20 \mathrm{MPa}$, respectively. Sulfonamide standard substance is $5.0 \mathrm{mg}$ and the sample weight is $4.8-5.2 \mathrm{mg}$, with $90 \mathrm{~s}$ oxygen-adding time.

Scanning electron microscope (SEM, TM3030, Hitachi High-Technologies, Tokyo, Japan) was used to observe the section topography of sample at an accelerating voltage of $5 \mathrm{kV}$. The sample was cut into slices about $80 \mu \mathrm{m}$ thick then dry at $105^{\circ} \mathrm{C}$ for $2 \mathrm{~h}$.

The X-ray photoelectron spectroscopy (XPS, Perkin Elmer, Waltham, MA, USA) analyses were carried out with a PHI-5400 electron spectrometer and using a monochromatic $\mathrm{Al} \mathrm{K \alpha}$ source (1486.6 $\mathrm{eV}$ ). Survey spectra were recorded in $1.0 \mathrm{eV}$ steps and $200 \mathrm{eV}$ analyzer pass energy. The samples were prepared with a thoroughly cleaned and vacuum drying.

\section{Results and Discussion}

\subsection{Determination of Lignin, Cellulose, and Hemicellulose}

The change in Klason lignin is opposite to that in the carbohydrate portions and extractive compounds. As listed in Table 1, the content of lignin in CS is about $31.37 \%$, which is lower than that of the samples LS-M (34.00\%) and LS-I (34.51\%), but higher than that of LS-O (30.05\%). This may be attributed to the chemical degradation of cellulose, hemicellulose, inorganic elements and extractive, resulting in the increased relative content of lignin [20]. Another reason for this could be the tree used to build the structure had a higher lignin content to begin with. In comparison, because the sample LS-O is exposed to the sun and ultraviolet light longer than both LS-M and LS-I, the lignin degrades more, thus showing the least content of Klason lignin. 
Table 1. The content (wt \%) of lignin (Klason lignin), cellulose, hemicellulose, and holocellulose, for the archaeological and fresh wood examined in this study.

\begin{tabular}{ccccc}
\hline Composition & CS & LS-O & LS-M & LS-I \\
\hline Klason lignin (wt \%) & 31.37 & 30.05 & 34.00 & 34.51 \\
Holocellulose (wt \%) & 66.85 & 56.65 & 63.33 & 59.42 \\
Cellulose (wt \%) & 46.53 & 41.87 & 45.29 & 43.63 \\
Hemicellulose (wt \%) & 20.32 & 14.78 & 18.04 & 15.79 \\
\hline
\end{tabular}

\subsection{FTIR Analysis}

As shown in Figure 2, the $3409 \mathrm{~cm}^{-1}$ band is ascribed to the stretching vibration of hydroxyl groups $(-\mathrm{OH})$ [21-24]. The sample LS-O has the lowest intensity followed by sample LS-I, which indicated the occurrence of dehydration during natural ageing. Compared with the fresh wood, the stretching vibration peak $\left(2924 \mathrm{~cm}^{-1}\right)$ of methyl $\left(-\mathrm{CH}_{3}\right)$ and methylene $\left(-\mathrm{CH}_{2}-\right)$ [25] in three samples of natural aging wood becomes flat and the LS-O shows the smallest absorption intensity. The peaks in FTIR at $1735 \mathrm{~cm}^{-1}$ were due to the $\mathrm{C}=\mathrm{O}$ stretching vibration in xylan [26]. Interestingly, the ancient wood sample does not show an absorption peak at around $1735 \mathrm{~cm}^{-1}$ belonging to the stretching vibration of the carbon-oxygen double bond in acetyl $\left(\mathrm{CH}_{3} \mathrm{C}=\mathrm{O}\right)$ group of xylan, indicating a very low content of hemicellulose in the ancient wood sample. The stretching vibration located at $1602 \mathrm{~cm}^{-1}$ of the conjugated carbonyl in the side chain of the lignin [26] structural unit shows that the characteristic peak of the natural aged fir is still obvious. This means that the lignin only slightly degrades. The signals at 1510 and $1423 \mathrm{~cm}^{-1}$ correspond to the aromatic skeletal vibrations and the aromatic skeletal vibrations combined with C-H in-plane deformation [27], respectively. LS-O has the lowest intensity followed by sample LS-I and CS whereas the LS-M has the highest intensity due to the degradation of the aromatic structures. This is consistent with the previous determination of Klason lignin content.

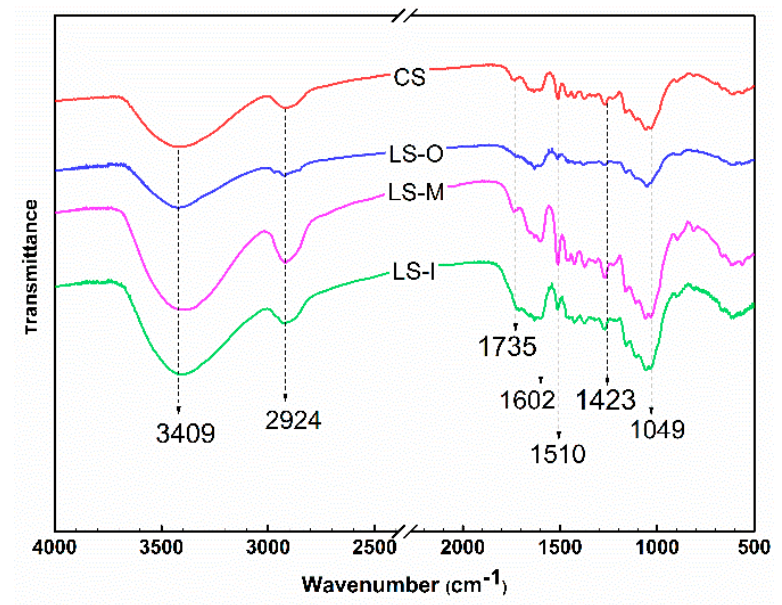

Figure 2. Infrared spectra of CS, LS-O, LS-M and LS-I.

\section{3. $P y-G C / M S$}

Furans compounds are used to analyze the fresh Chinese fir, and furfural compounds derive from cellulose and hemicellulose whereas aromatic compounds are from lignin. Figure 3 shows the detailed data for the pyrolysis products from Chinese fir and aged Chinese fir, with each peak corresponding to one specific compound. It is found that the peaks of Chinese fir are basically similar to the aged one, indicating that ageing does not change the chemical compositions of the pyrolysis products. The peaks between a Retention time (RT) from 9.73 to 28.27 (Tables S1-S4) belong to aromatic compounds corresponding to the intensity peak. As compared with the fresh wood, ageing Chinese fir also shows the peak for aromatic compounds but the intensity does not reduce. Aromatic compounds are produced by the rapid pyrolysis of lignin, proving that the benzene ring structure of lignin is not destroyed or 
changed significantly after natural aging due to the chemically stable six-membered ring symmetry structure of the benzene ring. The peaks at a RT range below 9.01 are ascribed to carbohydrate compounds and the peak intensity of naturally aged one less than nine is much weaker than that of fresh wood. Because these carbohydrates are mainly produced by the thermal decomposition of cellulose and hemicellulose, therefore some cellulose and hemicellulose of natural aging fir are decomposed and lost during natural ageing. More importantly, the pyrolysis peaks at RT $=12.98,17.4$, 19.5, and 23.04, respectively, correspond to guaiacol, 4-methyl guaiacol, 2-methoxy-4-Vinylphenol, and trans-2-methoxy-4-o-propenyl phenol. They are primarily derived from guaiacol-based phenolic monomers in lignin, indicating that lignin in Chinese fir is mainly composed of guaiacol monomer.
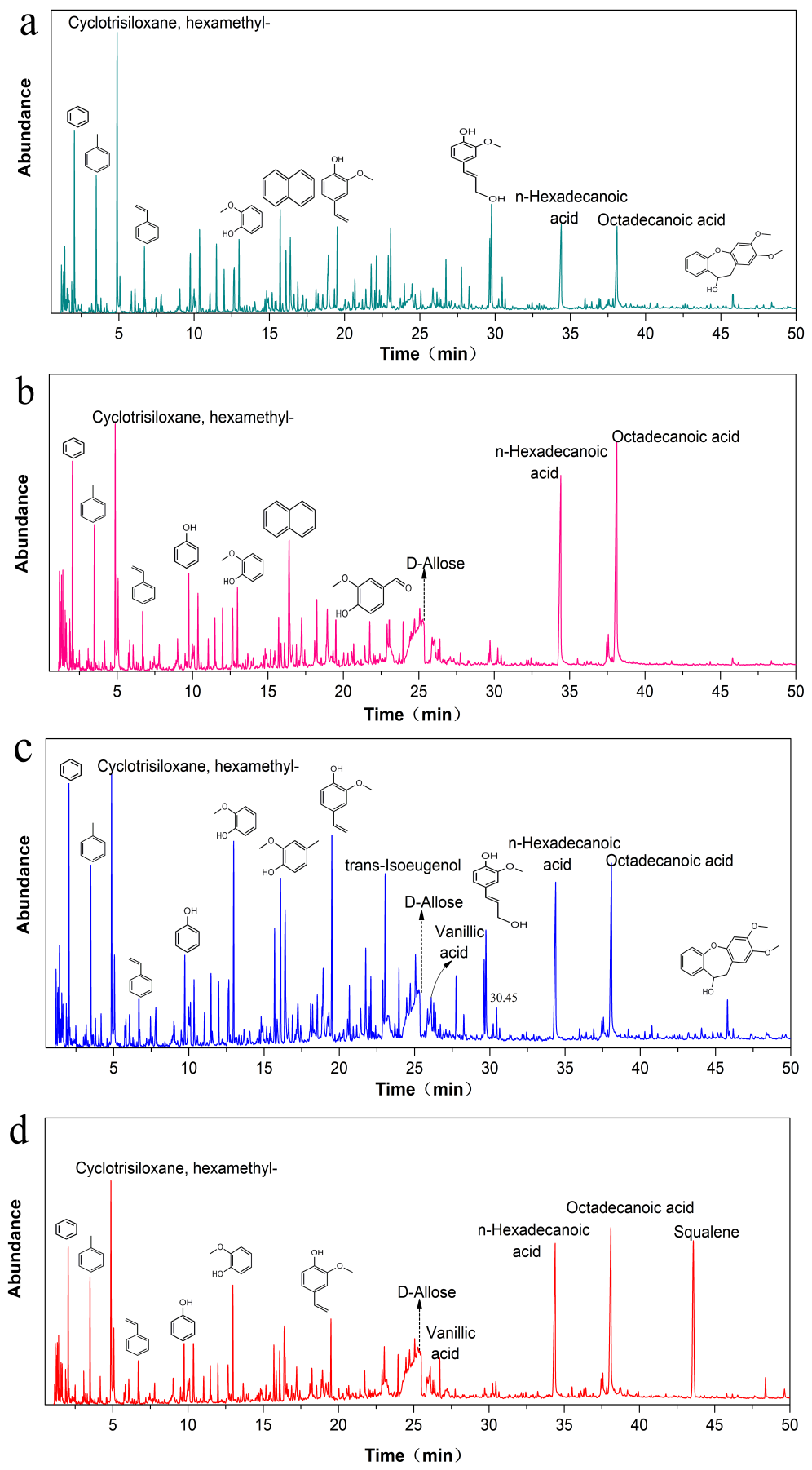

Figure 3. Detailed Py-GC/MS data for (a) CS, (b) LS-O, (c) LS-M, and (d) LS-I. 
The content of phenolic derivatives in the sample LS-I is higher than that of LS-O and LS-M. This is because the aging degree of the sample LS-I is higher than that of LS-M resulting in the increased relative content of lignin. However, the content of phenolic derivatives in LS-O is the lowest, because the content of lignin in LS-O is the lowest due to the sample was exposed to sunlight and air for a long time. As compared with the control fresh wood, the intensities of these peaks for naturally-aged Chinese fir pyrolysis compounds decrease. Unexpectedly, the content of phenolic derivatives in the aged wood samples is higher than that of fresh wood. Hence, the main difference between archaeological lignin and sound lignin may be that the archaeological lignin contains a relatively higher content of phenolic derivatives. Another reason for this could be the tree used to build the structure had a higher phenolic derivatives content to begin with.

As shown in Figure 4 (The data in the figure is obtained according to Tables S1-S4), the pyrolyzed products of CS, LS-M, LS-I, and LS-O, respectively, exhibit $25.44 \%, 30.02 \%, 30.35 \%$, and $23.41 \%$ of aromatic compounds. This is because of the significant degradation of both hemicellulose and cellulose whereas the lignin almost does not decompose in naturally aged fir, thereby leading to a decrease in the relative content of carbohydrates in the pyrolyzed products. As a result, the relative content of aromatic hydrocarbons in the pyrolysis products from ancient wood increases with the degree of aging.

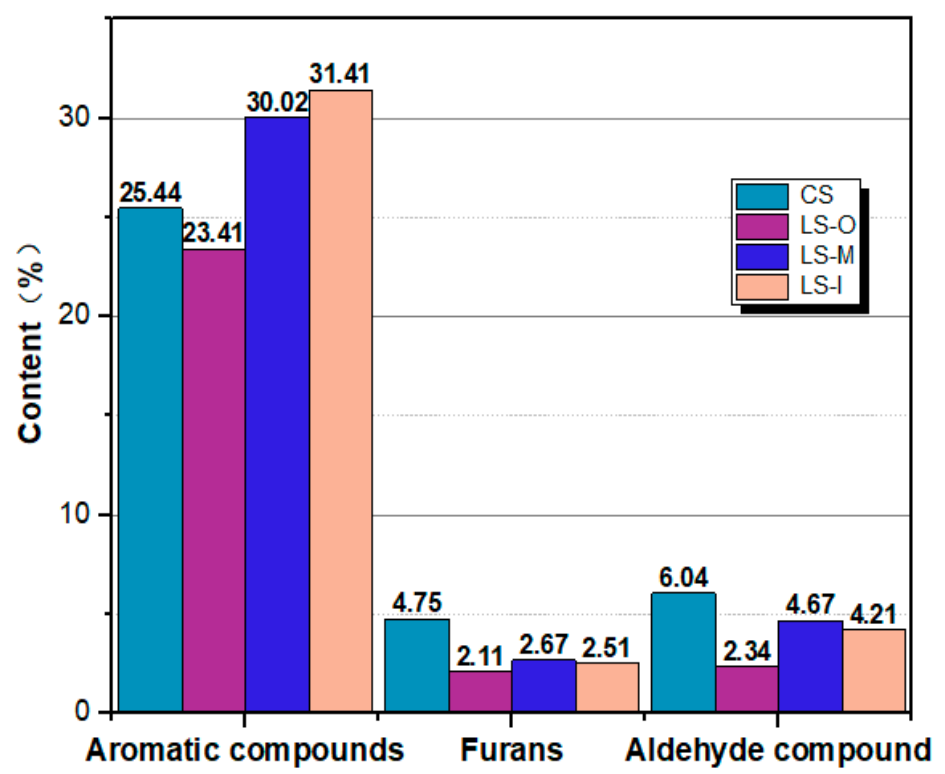

Figure 4. Main pyrolysis products contents for CS LS-O LS-M and LS-I obtained from Py-GC/MS measurements.

\subsection{Elemental Analysis}

Cellulose mainly contains three kinds of elements, namely carbon, hydrogen, and oxygen, with a chemical composition of $44.2 \%, 6.3 \%$, and $49.5 \%$, respectively. In comparison, lignin is composed of $60.04 \%$ C, $5.98 \% \mathrm{H}$, and $31.29 \%$ O. As summarized in Table 2, compared to the LS-M the content of elements carbon and hydrogen in sample LS-O and LS-I decreases but the content of oxygen increases due to the more severe oxidation of lignin and cellulose occurred in the aging process. Compared with CS the content of elements carbon, hydrogen in naturally aged samples all decrease but the content of oxygen increase. This may be the result of the oxidation of cellulose, lignin and hemicellulose, but it can not exclude that it is caused by the tree used to build the structure had higher oxygen element content.

Meanwhile, the content of both elements $\mathrm{N}$ and $\mathrm{S}$ in ancient Chinese fir are obviously higher than that of the fresh wood and the LS-O shows the highest contents of N and S, followed by LS-M and then LS-I. This is because the timber in the buildings is seriously attacked by acid rains, which usually contains a certain content of $\mathrm{SO}_{2}$ and $\mathrm{NO}_{2}$ in ancient Chinese fir with long-term exposure to external environments. In this study, the ancient wood samples were taken from the windows of 
ancient buildings. In the process of natural aging, the sample LS-I was also affected by the flowing humid air containing $\mathrm{H}_{2} \mathrm{SO}_{3}\left(\mathrm{SO}_{2}+\mathrm{H}_{2} \mathrm{O}=\mathrm{H}_{2} \mathrm{SO}_{3}\right)$ when the windows are open sometimes, thus resulting in the increase of $\mathrm{S}$ content.

Table 2. The elemental analysis results of the CS, LS-O, LS-M, and LS-I.

\begin{tabular}{|c|c|c|c|c|c|}
\hline Sample & $C(w t \%)$ & $H(w t \%)$ & $\mathrm{O}^{1}(w \mathrm{w} \%)$ & N (wt \%) & $S(w t \%)$ \\
\hline CS & 48.79 & 6.90 & 44.29 & 0 & 0.018 \\
\hline LS-M & 47.83 & 6.75 & 44.62 & 0.64 & 0.161 \\
\hline LS-I & 47.52 & 6.67 & 45.10 & 0.62 & 0.094 \\
\hline LS-O & 47.24 & 6.53 & 45.31 & 0.76 & 0.164 \\
\hline
\end{tabular}

${ }^{1}$ The content of oxygen $(\mathrm{O})$ is based on relative contents of elements $\mathrm{C}, \mathrm{H}, \mathrm{N}$, and $\mathrm{S}$.

\subsection{XRD}

As presented in Table 3, there is no significant change observed in the peak shape for the four samples except for the intensity. The crystalline morphology of cellulose in Chinese fir is found to only slightly change after many years of natural ageing. The intensity of diffraction peaks for naturally aged fir is significantly increased, which is due to the significant loss of hemicellulose but slight loss of cellulose, thereby retaining the cellulose crystalline zone. It can be found that in Table 3 and Figure S1, the crystallinity of ancient wood decreases with respect to that of fresh wood. In addition, the crystallinity of ancient wood decreases in the order of LS-O $<$ LS-I $<$ LS-M, which is due to the loss of cellulose that leads to reduced crystallinity.

Table 3. The degree of crystallinity of different samples.

\begin{tabular}{ccccc}
\hline Sample Number & CS & LS-O & LS-M & LS-I \\
\hline Degree of crystallinity (\%) & 35.89 & 32.04 & 35.81 & 34.62 \\
\hline
\end{tabular}

\subsection{Thermal Analysis}

Hemicellulose shows the lowest thermal stability in the wood components and starts to degrade around about $225^{\circ} \mathrm{C}$, with a rapid degradation temperature range of $210-320^{\circ} \mathrm{C}$. In contrast, cellulose is more thermally stable, showing a narrow thermal degradation temperature range between 300 and $375^{\circ} \mathrm{C}$. As compared with hemicellulose and cellulose, the aromatic structure makes lignin exhibit the highest thermal stability. Its thermal decomposition mainly takes place between $250-500{ }^{\circ} \mathrm{C}$ and decompose fastest between $310-420^{\circ} \mathrm{C}[28,29]$. Due to the differences in the structure, content and physical properties, these three major components demonstrate different pyrolysis characteristics but may mutually interfere in the thermal degradation process because of their strong interactions [30].

As shown in Figure 5, there are no identified weight losses for four samples before $200{ }^{\circ} \mathrm{C}$ and the decomposition starts from $268-300{ }^{\circ} \mathrm{C}$. The maximum weight loss peak of CS appears at about $383^{\circ} \mathrm{C}$ and the weight loss process ends at about $400{ }^{\circ} \mathrm{C}$, leaving a final residue of $19.89 \%$. In the case of the aged wood, LS-M, LS-I, and LS-O, respectively, exhibit a maximum weight loss peak at $360{ }^{\circ} \mathrm{C}, 369^{\circ} \mathrm{C}$ and $357^{\circ} \mathrm{C}$. The pyrolysis of both lignin and hemicellulose is mainly through the removal of side chains followed by the depolymerization of polymer chain and intramolecular dehydration. During the natural aging, lignin, and hemicellulose degrade to generate low molecular weight substances, resulting in increased lateral chains on hemicellulose and lignin. The increase of side chains leads to the decrease in the initial pyrolysis temperature and the temperature of rapid pyrolysis. LS-O shows the lowest maximum degradation temperature due to its lowest contents of lignin, cellulose, and hemicellulose [31]. 

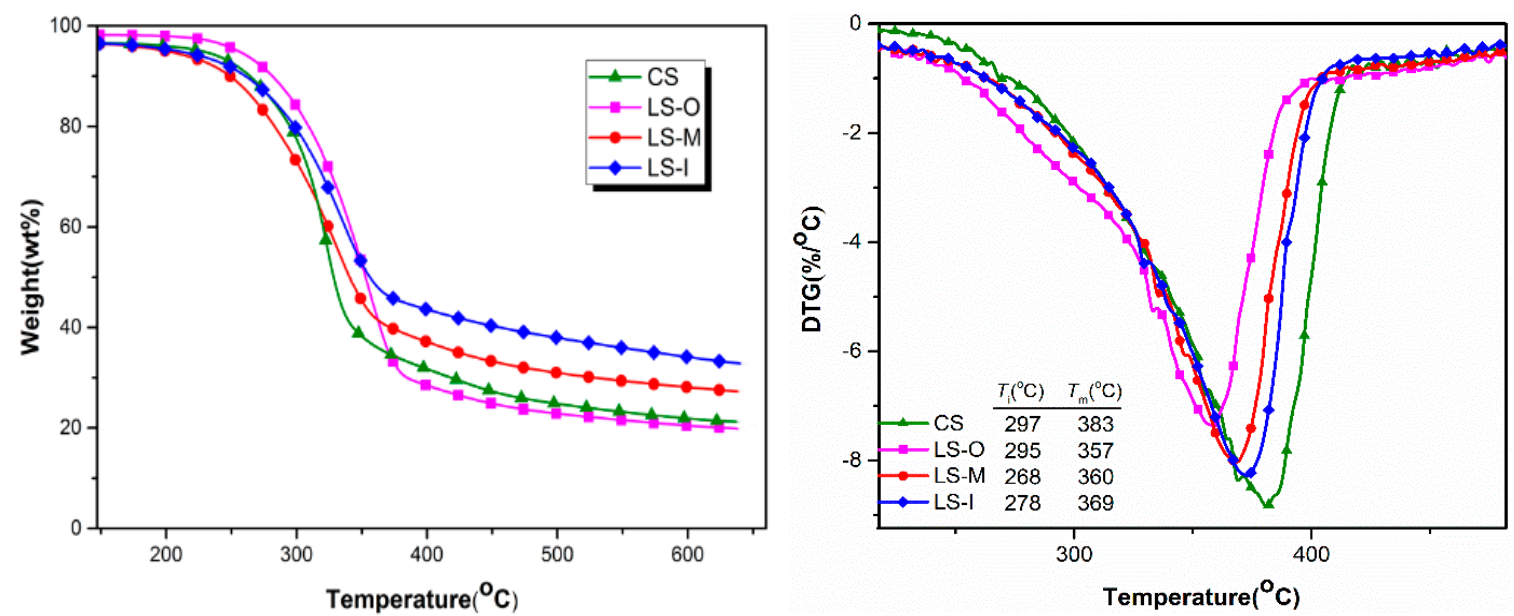

Figure 5. Thermal Gravity Analysis (TG)/Differential thermal gravity (DTG) analysis curves of different samples. Notes: Ti and Tm refer to the temperature where starting decomposition and the maximum mass loss occur.

LS-O, LS-M, and LS-I show a final residue mass of $21.73 \%, 27.21 \%, 32.75 \%$, respectively. TG results show that the onset pyrolysis temperature of all the samples does not change significantly and all of them start to pyrolyze at $268-300{ }^{\circ} \mathrm{C}$. Due to different contents of the three major components, the maximum weight loss peak has a slight difference. The LS-I was the highest residue, about $32.75 \%$, while the difference in the other groups is just about $3-8 \%$. This is due to the degradation of cellulose and the relative increase content of lignin, thus leading the wood sample to exhibiting high content of carbon.

\subsection{Morphology Observation}

Figure 6 clearly shows that the pith structure of fresh wood is integral whereas that of the ancient wood is deformed with some filamentous residue attached. At higher magnifications, we can observe the more intact xylem cells and intercellular layer structures. The cell wall of the sample LS-M slightly changes. In comparison, that of LS-I becomes thinner but the damage degree is less than that of LS-O (Figure S2). These are due to the large loss of cellulose and hemicellulose in aged Chinese fir, resulting in an increase in the intercellular space and a deformation of cell compartment well consistent with the results of FTIR and Py-GC/MS. Figure 7 illustrates the proposed process for the loss of cellulose and hemicellulose of timbers in buildings.
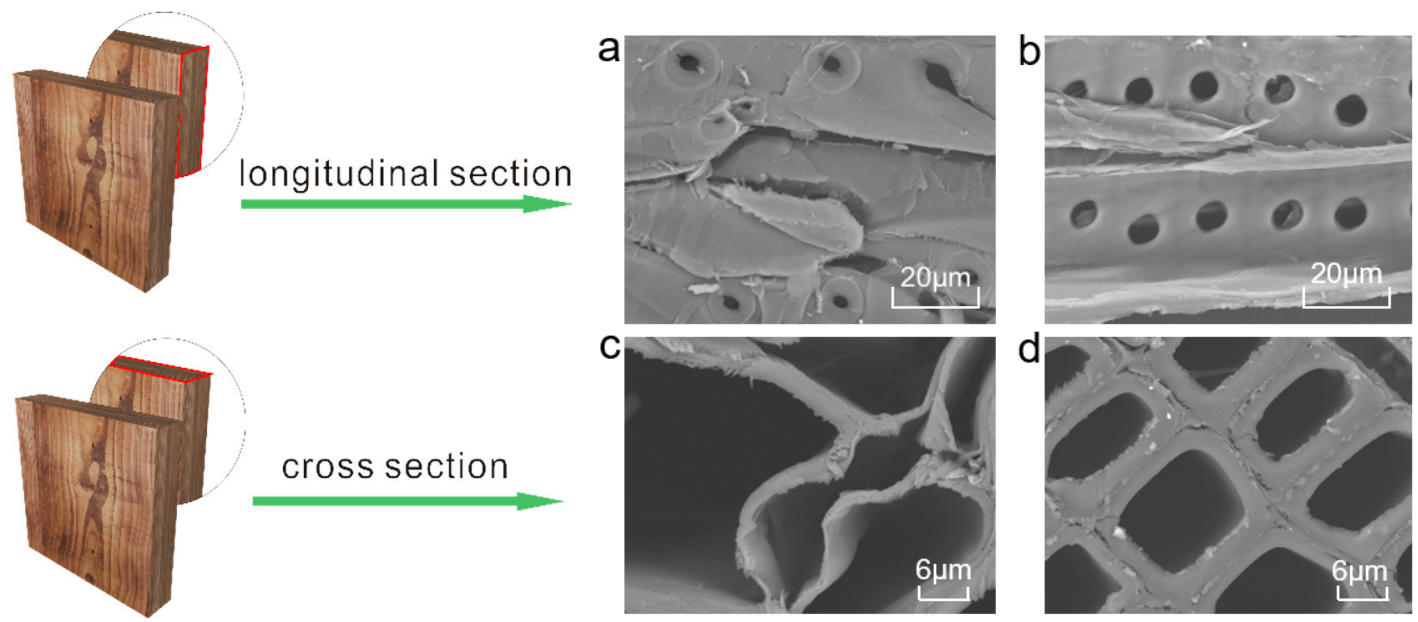

Figure 6. SEM images of the cross-section topography of (a) and (c) the outer layer of ancient timbers, (b) and (d) the control fresh samples. 


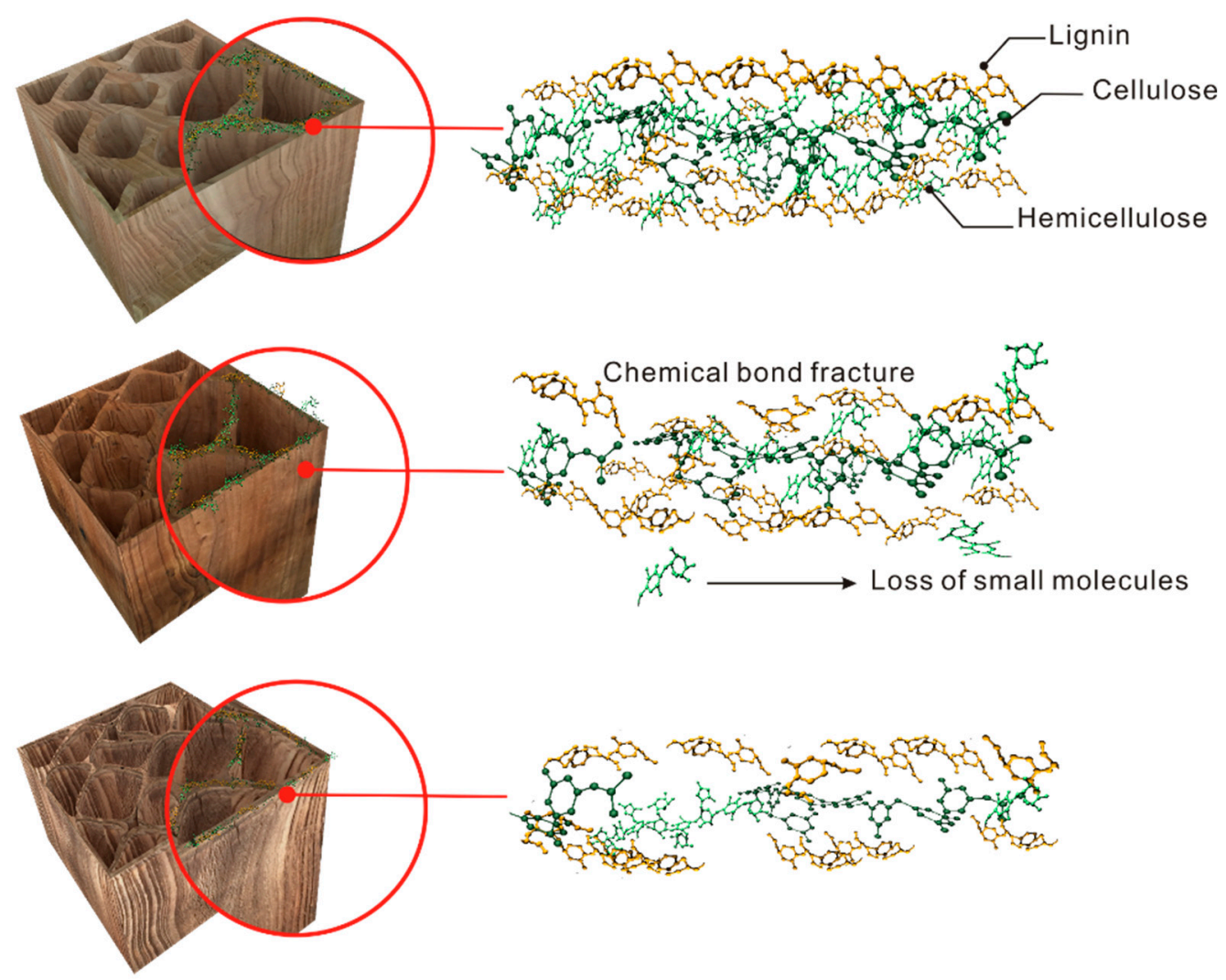

Figure 7. Schematic illustration of the change of three major components in the timber in the ancient buildings in the natural aging process.

\subsection{XPS}

To gain an insightful understanding on the change of various functional groups, the $\mathrm{C} 1 \mathrm{~s}$ spectrum is usually deconvoluted into three components according to the number of oxygen atoms bonded to C. The $\mathrm{C} 1$ class at a binding energy (BE) of $284.6 \mathrm{eV}$ corresponds to carbon atoms bonded only with carbon or hydrogen atoms. This peak mainly arises from lignin phenyl propane and fatty acids, fats and waxes and other hydrocarbons. The $\mathrm{C} 2$ class at a higher $\mathrm{BE}$ compared to $\mathrm{C} 1\left(\Delta_{\mathrm{BE}}=+1.5 \pm 0.2 \mathrm{eV}\right)$ reveals the carbon atoms bonded with one oxygen atom. A large number of carbon atoms in cellulose and hemicellulose molecules in wood are connected with hydroxyl $(-\mathrm{OH})$. In comparison, the $\mathrm{C} 3$ class belongs to carbon atoms bonded to a carbonyl or two non-carbonyl oxygen atoms $\left(\Delta_{\mathrm{BE}}=+2.8 \pm 0.2 \mathrm{eV}\right)$, representing the characteristic peaks of carbonyl groups and the oxidation in wood [2]. Figure 8a shows that LS-M gives rise to the highest C/O ratio relative to the reference sample and LS-I and LS-O because of the lowest oxidation degree. LS-O and LS-I exhibit a lower C/O ratio than the CS because the long-term exposure to the environment leads to oxidation. The considerable changes are observed on the sample LS-O and this variation can be explained by the removal of low molecular weight compounds as extractives, hemicelluloses and even a certain part of amorphous cellulose in the first period of ageing [32].

Based on the XPS results (Table 4 and Figure 8), we can calculate the proportion of three kinds of $\mathrm{C} 1$ s peaks. The CS shows the largest C2 peak whereas the sample LS-I exhibits the smallest peak. In addition, the maximum and the minimum $\mathrm{C} 3$ peaks are observed in LS-O and CS, respectively. The C2 (C-O groups) peak area reflects the characteristic structure of cellulose and hemicellulose. This means that the CS sample contains the most cellulose and hemicellulose. Similarly, the C3 peak reflects the oxidation degree of the lignin component on the timber surface. In brief, the degrees of oxidation of four samples are different and the oxidation of LS-O is the most serious whereas the CS shows the 
lowest degree of oxidation. Moreover, both cellulose and hemicellulose suffer more oxidation than the lignin.
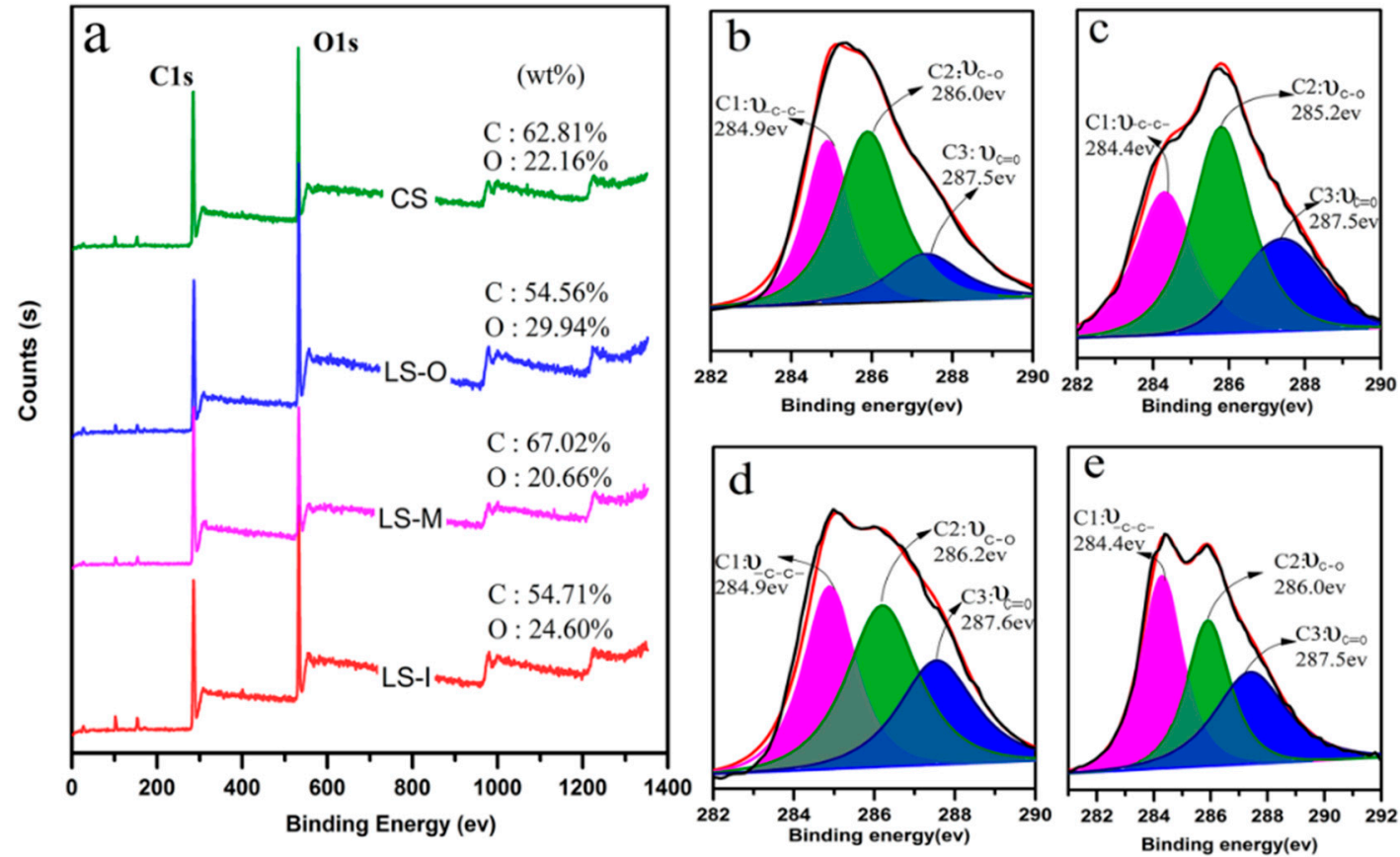

Figure 8. (a) X-ray photoelectron spectroscopy (XPS) survey spectra of four samples and C1s spectra of (b) CS, (c) LS-O, (d) LS-M, and (e) LS-I.

Table 4. Carbon peak area ratios for C1s binding energy for CS, LS-O, LS-M, and LS-I.

\begin{tabular}{cccc}
\hline \multirow{2}{*}{ Sample } & \multicolumn{3}{c}{ Peak Area Percentage (\%) } \\
\cline { 2 - 4 } & C1 (C-C) & C2 (C-O) & C3 (C=O) \\
\hline CS & 34 & 50 & 16 \\
LS-O & 31 & 35 & 34 \\
LS-M & 33 & 40 & 27 \\
LS-I & 38 & 30 & 32 \\
\hline
\end{tabular}

\section{Conclusions}

This work systematically investigates the changes of chemical structure and composition and morphology of timbers after many years of natural ageing in ancient Chinese buildings. Under the experimental conditions in this work, the inner layer of the ancient wood samples has the highest content of holocellulose, lignin and the crystallinity followed by the middle layer and then the outer layer. The content of aromatic compounds and aldehydes in pyrolysis products is also the highest in the middle layer and the dehydration of the outer layer is the most serious during wood aging. The outer layer of ancient wood undergoes the largest degradation as compared with the other two layers. Compared with the fresh wood samples, the ancient timbers show significant reductions in the content of cellulose and hemicellulose and their degrees of crystallinity. The crystalline zone of the cellulose in ancient wood samples is partially destroyed. The outer layer of the ancient timbers shows the higher degree of oxidation than the other two layers and the control of fresh wood due to long-term exposure to various environments. During natural ageing, both cellulose and hemicellulose loss leaving deformed pith structures whereas the chemical structure of lignin remains intact except for the outer layer due to long-term exposure to ultraviolet light. In brief, the outer layer of wood exhibits the most serious ageing, while the middle layer only undergoes slight ageing. This work offers an insightful understanding of the evolution of physical features of the ancient timber during a 
long-term natural ageing and thus provides guidelines for producing artificial ancient woods to repair the damaged ones in ancient Chinese architecture.

Supplementary Materials: The following are available online at http://www.mdpi.com/2073-4360/11/5/809/s1, Figure S1: XRD spectra for CS, LS-I, LS-O, and LS-M. Figure S2: SEM images of cross-section topography of ancient timbers, (a) LS-M and (b) LS-I. Table S1: The detailed results of PY-GC/MS test of samples at the RT range of 1-10 min. Table S2: The detailed results of PY-GC/MS test of samples at the RT range of 10-20 min. Table S3: The detailed results of PY-GC/MS test of samples at the RT range of 20-30 min. Table S4: The detailed results of PY-GC/MS test of samples at the RT range of 30-40 min.

Author Contributions: Conceptualization, Y.Y. and X.Z.; formal analysis, Y.Y. and P.S.; investigation, W.Z.; writing - original draft preparation, C.Z. and X.Z.; writing — review and editing, C.Z. and L.L.

Funding: This research was funded by the Natural Science Foundation of Zhejiang province (Grant No. LY16C160010) and the National Science Foundation of China (Grant No. 51873196).

Acknowledgments: I would like to express my sincere thanks to Yifei Cheng who assisted in the course of my writing this paper.

Conflicts of Interest: The authors declare no conflict of interest.

\section{References}

1. Colombini, M.P.; Lucejko, J.J.; Modugno, F.; Orlandi, M.; Tolppa, E.-L.; Zoia, L. A multi-analytical study of degradation of lignin in archaeological waterlogged wood. Talanta 2009, 80, 61-70. [CrossRef] [PubMed]

2. Inari, G.N.; Petrissans, M.; Lambert, J.; Ehrhardt, J.J.; Gérardin, P. XPS characterization of wood chemical composition after heat-treatment. Surf. Interface Anal. 2006, 38, 1336-1342. [CrossRef]

3. Popescu, C.-M.; Dobele, G.; Rossinskaja, G.; Dizhbite, T.; Vasile, C. Degradation of lime wood painting supports. J. Anal. Appl. Pyrolysis 2007, 79, 71-77. [CrossRef]

4. Popescu, C.-M.; Hill, C.A.S. The water vapour adsorption-desorption behaviour of naturally aged Tilia cordata Mill. wood. Polym. Degrad. Stab. 2013, 98, 1804-1813. [CrossRef]

5. Bardet, M.; Foray, M.F.; Maron, S.; Goncalves, P.; Trân, Q.K. Characterization of wood components of Portuguese medieval dugout canoes with high-resolution solid-state NMR. Carbohydr. Polym. 2004, 57, 419-424. [CrossRef]

6. Sandak, A.; Sandak, J.; Babiński, L.; Pauliny, D.; Riggio, M. Spectral analysis of changes to pine and oak wood natural polymers after short-term waterlogging. Polym. Degrad. Stab. 2014, 99, 68-79. [CrossRef]

7. Tamburini, D.; Łucejko, J.J.; Modugno, F.; Colombini, M.P. Characterisation of archaeological waterlogged wood from Herculaneum by pyrolysis and mass spectrometry. Int. Biodeterior. Biodegrad. 2014, 86, 142-149. [CrossRef]

8. Colombini, M.P.; Orlandi, M.; Modugno, F.; Tolppa, E.L.; Sardelli, M.; Zoia, L.; Crestini, C. Archaeological wood characterisation by PY/GC/MS, GC/MS, NMR and GPC techniques. Microchem. J. 2007, 85, 164-173. [CrossRef]

9. Łucejko, J.J.; Modugno, F.; Ribechini, E.; del Río, J.C. Characterisation of archaeological waterlogged wood by pyrolytic and mass spectrometric techniques. Anal. Chim. Acta 2009, 654, 26-34. [CrossRef] [PubMed]

10. Sáiz-Jiménez, C.; Boon, J.J.; Hedges, J.I.; Hessels JK, C.; De Leeuw, J.W. Chemical characterization of recent and buried woods by analytical pyrolysis Comparison of pyrolysis data with 13C NMR and wet chemical data. J. Anal. Appl. Pyrolysis 1987, 11, 437-450. [CrossRef]

11. Vinciguerra, V.; Napoli, A.; Bistoni, A.; Petrucci, G.; Sgherzi, R. Wood decay characterization of a naturally infected London plane-tree in urban environment using Py-GC/MS. J. Anal. Appl. Pyrolysis 2007, 78, 228-231. [CrossRef]

12. Yeh, T.-F.; Yamada, T.; Capanema, E.; Chang, H.-M.; Chiang, V.; Kadla, J.F. Rapid Screening of Wood Chemical Component Variations Using Transmittance Near-Infrared Spectroscopy. J. Agric. Food Chem. 2005, 53, 3328-3332. [CrossRef] [PubMed]

13. Belkhir, S.; Koubaa, A.; Khadhri, A.; Ksontini, M.; Nadji, H.; Smiti, S.; Stevanovic, T. Seasonal effect on the chemical composition of the leaves of Stipa tenacissima L. and implications for pulp properties. Ind. Crop. Prod. 2013, 44, 56-61. [CrossRef]

14. Labidi, K.; Korhonen, O.; Zrida, M.; Hamzaoui, A.H.; Budtova, T. All-cellulose composites from alfa and wood fibers. Ind. Crop. Prod. 2019, 127, 135-141. [CrossRef] 
15. Fahmi, R.; Bridgwater, A.V.; Thain, S.C.; Donnison, I.S.; Morris, P.M.; Yates, N. Prediction of Klason lignin and lignin thermal degradation products by Py-GC/MS in a collection of Lolium and Festuca grasses. J. Anal. Appl. Pyrolysis 2007, 80, 16-23. [CrossRef]

16. Lu, Q.; Yang, X.C.; Dong, C.Q.; Zhang, Z.F.; Zhang, X.M.; Zhu, X.F. Influence of pyrolysis temperature and time on the cellulose fast pyrolysis products: Analytical Py-GC/MS study. J. Anal. Appl. Pyrolysis 2011, 92, 430-438. [CrossRef]

17. Lu, Q.; Li, W.Z.; Zhang, D.; Zhu, X.F. Analytical pyrolysis-gas chromatography/mass spectrometry (Py-GC/MS) of sawdust with Al/SBA-15 catalysts. J. Anal. Appl. Pyrolysis 2009, 84, 131-138. [CrossRef]

18. Zhang, M.; Resende, F.L.P.; Moutsoglou, A.; Raynie, D.E. Pyrolysis of lignin extracted from prairie cordgrass, aspen, and Kraft lignin by Py-GC/MS and TGA/FTIR. J. Anal. Appl. Pyrolysis 2012, 98, 65-71. [CrossRef]

19. Thygesen, A.; Oddershede, J.; Lilholt, H.; Thomsen, A.B.; Ståhl, K. On the determination of crystallinity and cellulose content in plant fibres. Cellulose 2005, 12, 563-576. [CrossRef]

20. Xie, J.; Qi, J.; Huang, X.; Zhou, N.; Hu, Y. Comparative analysis of modern and ancient buried Phoebe zhennan wood: Surface color, chemical components, infrared spectroscopy, and essential oil composition. J. For. Res. 2015, 26, 501-507. [CrossRef]

21. Song, P.; Dai, J.; Chen, G.; Yu, Y.; Fang, Z.; Lei, W.; Fu, S.; Wang, H.; Chen, Z.-G. Bioinspired Design of Strong, Tough, and Thermally Stable Polymeric Materials via Nanoconfinement. ACS Nano 2018, 12, 9266-9278. [CrossRef] [PubMed]

22. Song, P.; Xu, Z.; Dargusch, M.S.; Chen, Z.-G.; Wang, H.; Guo, Q. Granular Nanostructure: A Facile Biomimetic Strategy for the Design of Supertough Polymeric Materials with High Ductility and Strength. Adv. Mater. 2017, 29, 1704661. [CrossRef] [PubMed]

23. Song, P.; Xu, Z.; Lu, Y.; Guo, Q. Bio-Inspired Hydrogen-Bond Cross-Link Strategy toward Strong and Tough Polymeric Materials. Macromolecules 2015, 48, 3957-3964. [CrossRef]

24. Song, P.A.; Xu, Z.; Guo, Q. Bioinspired Strategy to Reinforce PVA with Improved Toughness and Thermal Properties via Hydrogen-Bond Self-Assembly. ACS Macro Lett. 2013, 2, 1100-1104. [CrossRef]

25. Sharma, P.R.; Sharma, S.K.; Antoine, R.; Hsiao, B.S. Efficient Removal of Arsenic Using Zinc Oxide Nanocrystal-Decorated Regenerated Microfibrillated Cellulose Scaffolds. ACS Sustain. Chem. Eng. 2019, 7, 6140-6151. [CrossRef]

26. Sharma, P.R.; Chattopadhyay, A.; Sharma, S.K.; Geng, L.; Amiralian, N.; Martin, D.; Hsiao, B.S. Nanocellulose from Spinifex as an Effective Adsorbent to Remove Cadmium(II) from Water. ACS Sustain. Chem. Eng. 2018, 6, 3279-3290. [CrossRef]

27. Sharma, P.R.; Chattopadhyay, A.; Sharma, S.K.; Hsiao, B.S. Efficient Removal of UO22+ from Water Using Carboxycellulose Nanofibers Prepared by the Nitro-Oxidation Method. Ind. Eng. Chem. Res. 2017, 56, 13885-13893. [CrossRef]

28. Hosoya, T.; Kawamoto, H.; Saka, S. Cellulose-hemicellulose and cellulose-lignin interactions in wood pyrolysis at gasification temperature. J. Anal. Appl. Pyrolysis 2007, 80, 118-125. [CrossRef]

29. Hosoya, T.; Kawamoto, H.; Saka, S. Pyrolysis behaviors of wood and its constituent polymers at gasification temperature. J. Anal. Appl. Pyrolysis 2007, 78, 328-336. [CrossRef]

30. Wang, S.; Guo, X.; Wang, K.; Luo, Z. Influence of the interaction of components on the pyrolysis behavior of biomass. J. Anal. Appl. Pyrolysis 2011, 91, 183-189. [CrossRef]

31. Isogai, A.; Saito, T.; Fukuzumi, H. TEMPO-oxidized cellulose nanofibers. Nanoscale 2011, 3, 71-85. [CrossRef] [PubMed]

32. Popescu, C.-M.; Tibirna, C.-M.; Vasile, C. XPS characterization of naturally aged wood. Appl. Surf. Sci. 2009, 256, 1355-1360. [CrossRef]

(C) 2019 by the authors. Licensee MDPI, Basel, Switzerland. This article is an open access article distributed under the terms and conditions of the Creative Commons Attribution (CC BY) license (http://creativecommons.org/licenses/by/4.0/). 